\title{
Compressive Strength of CFRP Confined Concrete under Exposure to High Temperature
}

\author{
Nur Aiman Suparlan', Hazrina Ahmad ${ }^{2, *}$, Mohd Hisbany Mohd Hashim', \\ Muhammad Amir Shafiq Rahamad $\mathrm{Ali}^{2}$, Ruqayyah Ismail ${ }^{2}$, Fariz Aswan Ahmad Zakwan ${ }^{2}$ \\ ${ }^{1}$ Faculty of Civil Engineering, Universiti Teknologi MARA (UiTM) 40450 Shah Alam Selangor, Malaysia \\ ${ }^{2}$ Faculty of Civil Engineering, Universiti Teknologi MARA (UiTM) Cawangan Pulau Pinang, Kampus Permatang Pauh, 13500 \\ Permatang Pauh, Pulau Pinang, Malaysia
}

Received February 20, 2021; Revised July 26, 2021; Accepted August 14, 2021

\section{Cite This Paper in the following Citation Styles}

(a): [1] Nur Aiman Suparlan, Hazrina Ahmad, Mohd Hisbany Mohd Hashim, Muhammad Amir Shafiq Rahamad Ali, Ruqayyah Ismail, Fariz Aswan Ahmad Zakwan, "Compressive Strength of CFRP Confined Concrete under Exposure to High Temperature," Civil Engineering and Architecture, Vol. 9, No. 5A, pp. 78 - 85, 2021. DOI: 10.13189/cea.2021.091309.

(b): Nur Aiman Suparlan, Hazrina Ahmad, Mohd Hisbany Mohd Hashim, Muhammad Amir Shafiq Rahamad Ali, Ruqayyah Ismail, Fariz Aswan Ahmad Zakwan (2021). Compressive Strength of CFRP Confined Concrete under Exposure to High Temperature. Civil Engineering and Architecture, 9(5A), 78 - 85. DOI: 10.13189/cea.2021.091309.

Copyright $\odot 2021$ by authors, all rights reserved. Authors agree that this article remains permanently open access under the terms of the Creative Commons Attribution License 4.0 International License

\begin{abstract}
Currently, in Malaysia, there has been an alarming number of fire breakouts that not only concern the lives of the residents but also the integrity of the exposed structures themselves. Exposure to high temperature may result in significant damage to reinforced concrete structures such as losses in strength, thus affecting its mechanical and physical properties. The chances of re-using the structure after the event of a fire by means of applying certain retrofitting measures are mainly dependent on the residual load-bearing capacity and an acceptable residual deflection. The structural design of buildings should be carried out so that a structure is able to maintain its stability and strength throughout its service life, including design consideration on fire resistance. This research was carried out to study the effectiveness of the carbon fiber reinforced polymer (CFRP) sheet to strengthened concrete cylinders under high temperatures $\left(600^{\circ} \mathrm{C}\right.$ and $\left.800^{\circ} \mathrm{C}\right)$. The study will focus on the effect of high temperature on compressive strength as well as the effect of high temperature on the CFRP concrete cylinder. Eighteen (18) concrete cylinder samples of $300 \mathrm{~mm}$ height and $150 \mathrm{~mm}$ diameter were fabricated, which consist of six (6) control samples (without CFRP), six (6) CFRP concrete cylinder and the remaining three (3) CFRP concrete cylinders were insulated with fire protection mortar. The average strength loss of the control sample (without CFRP), when exposed to $600^{\circ} \mathrm{C}$, is about $28 \%$ compared to
\end{abstract}

control samples. The average compressive strength of the CFRP concrete cylinder exposed to $600^{\circ} \mathrm{C}$ is increased by about $9 \%$ compared to the control sample. Fire protection mortar can prevent the concrete cylinder from spalling, major cracks and combustion of CFRP at high temperature. The knowledge in this research field can be used as the basis for structural rehabilitation work.

Keywords Carbon Fiber Reinforced Polymer, Concrete Cylinder, Compressive Strength, High Temperature, Fire Protection Mortar

\section{Introduction}

Currently, in Malaysia, there have been an alarming number of fire breakouts that not only concern the lives of the residences but also the integrity of the exposed structures themselves. Exposure to high temperature may result in significant damage to reinforced concrete structures resulting losses in strength, thus affecting its mechanical and physical properties. The chances of re-using the structure after the event of a fire by means of applying certain retrofitting measures are mainly dependent on the residual load-bearing capacity and an acceptable residual deflection. The structural design of 
buildings should be carried out such that a structure is able to maintain its stability and strength throughout its service life, including design consideration on fire resistance.

One of the reinforced materials that are widely used for repairing all kinds of reinforced concrete structures is the carbon fiber reinforced polymer (CFRP). The CFRP is used as an external reinforcement to the concrete members. The main function of CFRP is to strengthen the structure capacity commonly found in bridge construction. CFRP strips are lighter, non-corrosive, and require less intense work than the application of the steel plate or exterior post-tensioning. These strips are proven to be effective in strengthening structural elements. The lightweight of CFRP strips has ten times the malleable strength of steel. CFRP has the capability of carrying loads in tension; this can be used to strengthen against flexural, shear or compression, depending on how the CFRP strips are oriented to the longitudinal reinforcing steel.

However, the application of CFRP wraps in buildings has been disrupted due to uncertainties regarding the way they behave under fire exposure. Most CFRP is vulnerable to combustion of their polymer matrix, possibly resulting in the increased of flame spread and toxic smoke evolution. The studies on the behavior of CFRP strengthened concrete members under fire conditions are still limited. Some studies found that the behavior of CFRP-strengthened concrete structures at normal temperature is satisfactory but there is very little information regarding the behavior of CFRP-strengthened concrete members under high temperature. The fire performance of CFRP-strengthened reinforced concrete structural members may raise concerns, where fire is one of the prime design considerations. Temperatures greater than $800^{\circ} \mathrm{C}$ are common in fires within buildings. Even a normal or spontaneous fire would exceed temperatures of up to $1000^{\circ} \mathrm{C}$, but usually above $800^{\circ} \mathrm{C}$, nearly all of concrete's compressive strengths were lost [1].

Reference [2] tested cylinders to investigate the strength, stiffness and permeability of concrete heated to various temperatures and cooling scenarios. The results demonstrated that the residual strength and stiffness dropped rapidly when the temperature was increased above $400^{\circ} \mathrm{C}$. At $600^{\circ} \mathrm{C}$ and $800^{\circ} \mathrm{C}$ the residual strength of concrete was found to be less than $57 \%$ and $18 \%$ of the original unheated strength respectively. The mechanical properties of concrete such as compressive strength, change with the increase of temperature. The changes generally depend on a few factors such as fire duration and temperature peak, rate of heating and cooling and type of testing. Three types of test conditions stressed, un-stressed, and un-stressed residual strength tests, have been used to investigate the performance of concrete in fire [3]. Reference [4] noted that fiber reinforced polymer composites had excellent properties such as high resilience, hardness, damping property, flexural strength and resistance to rust, wear, impact and fire, in addition to high strength to weight ratio.

Pre-load was also important when dealing with the structure especially concrete columns or cylinders in order to simulate the actual condition of the structure under loading. Reference [5] used pre-load levels of $20 \%, 50 \%$ and $80 \%$ of the unconfined concrete strength for the experimental works. It was discovered that the increasing temperatures decrease the concrete strength. There is a further decrease in cooling possibly due to the additional micro cracking. The quicklime (calcium oxide) absorbs moisture and transforms to slaked lime (calcium hydroxide) when concrete cools down. When this happens, fragmentation of the affected concrete will occur. Generally, in most concrete structures the residual strength of concrete stays approximately in the range of $75 \%$ to $25 \%$ of the original strength when heated in the range of $300^{\circ} \mathrm{C}$ to $600^{\circ} \mathrm{C}$, respectively [6].

The contribution of the CFRP wraps can be ignored during a fire unless sufficient insulation was provided. This statement could be related to the findings by Elsanadedy et al. [7]. The use of insulation materials increased the ultimate load of the columns (with respect to the uninsulated column). Thus, as the adhesive resin is softened at high temperatures, the CFRP concrete cylinder needs to be protected by a fire protection system such as a fire protection mortar. Reference [7], studied the effect of high temperature on the structural response of reinforced concrete circular column strengthening with fiber-reinforced polymer composites. It was found that CFRP wrapped column subject to $100^{\circ} \mathrm{C}$ and $200^{\circ} \mathrm{C}$, the epoxy appeared to melt while the columns were in the oven, however, post-cooling the epoxy regained its original form. Moreover, the CFRP composite was found to be charred at $300^{\circ} \mathrm{C}$ and $400^{\circ} \mathrm{C}$ but still adhered to the concrete surface.

According to [8], that studied random cross-sections, all CFRP confined components failed by the abrupt rupture of fibre sheets. The concrete underwent crush and disintegration in the areas of specimen failures. Reference [9] stated that the experimental program was carried out by making a concrete cylinder specimen in which the concrete compressive strength and temperatures as the parameters being examined. The findings of such tests were that when the specimen was burnt at a temperature of $300^{\circ} \mathrm{C}$, the deterioration of the steel fiber concrete compressive strength of the sample average quality control on all concrete was around 10 percent to 20 percent, where the degradation increases with the increasing compressive strength of concrete.

The purpose of this research is to fill in some of the gaps in understanding the effectiveness of the carbon fiber reinforced polymer (CFRP) sheet to increase the compressive strength of concrete cylinders under high temperature and the effect of high temperature on the CFRP concrete. The study will focus on the effect of high temperature on compressive strength as well as the effect 
of high temperature on the bonding of the CFRP sheet to the concrete cylinder surface.

\subsection{Problem Statement}

Designed structures should be able to maintain their stability and strength throughout their service life, including design consideration on fire resistance. Structural deterioration over time could be caused by weather, environment, natural disaster, excessive loading, poor workmanship and others. Retrofitting and strengthening have always been one of the chosen solutions to any deteriorated structures.

In the civil engineering field, the most common material used to retrofit and strengthen column structures is carbon fiber-reinforced polymer (CFRP). Its ability in improving bending, compressive strength as well as ductility of the structure caught wide researchers' attention to utilize this polymer. However, strengthened column structures are still exposed to the risk of fire occurrence subjecting the structure to high temperatures. The alarming number of fire breakouts not only concerns the lives involved but also the integrity of the exposed structure itself. As we all know, most Malaysian domestic structures are made of reinforced concrete.

In recent years, concrete cylinders wrapped with carbon fiber reinforced polymer (CFRP) have been widely studied for their use in civil engineering structures. However, the performance of these CFRP concrete systems exposed to high temperature is a serious concern due to the combustibility of CFRP and the bonding between CFRP and the concrete surface. Furthermore, previous studies [10] also shown that exposure to high temperatures has the tendency to cause degradation of bonding between the CFRP sheet with the concrete surface. Therefore, a detailed investigation on the effect of high temperature on this CFRP retrofitting technique is very crucial prior to the application of the system.

\section{Materials and Methods}

\subsection{Material}

Overall, 18 concrete cylinders of $300 \mathrm{~mm}$ in height and $150 \mathrm{~mm}$ in diameter were fabricated, which consists of control samples (without CFRP) and concrete cylinder wrapped with CFRP. The control samples were divided into two types; exposed to ambient temperature and exposed to high temperature $\left(600\right.$ and $800^{\circ} \mathrm{C}$ ) in the electric furnace. Meanwhile, for the CFRP wrapped concrete cylinders, three (3) samples were exposed to $600^{\circ} \mathrm{C}$ and six (6) samples were exposed to $800^{\circ} \mathrm{C}$. CFRP concrete cylinders exposed to $800^{\circ} \mathrm{C}$ are divided into two types which are three (3) CFRP concrete cylinder samples were insulated with fire protection mortar and the other three (3) samples were left without any fire protection.

\subsubsection{Concrete}

One batch of concrete mixture was prepared using the ordinary Portland cement and with the designed compressive strength of $30 \mathrm{MPa}$ in the concrete laboratory, Faculty of Civil Engineering UiTM Shah Alam for concrete casting. The procedure of the concrete mixing was carried out according to British Standard (BS 5328: 1981) in order for the compressive strength to reach approximately $30 \mathrm{MPa}$. Table 1 below shows the mix design used for casting of the 18 concrete cylinders with sizes of $300 \mathrm{~mm}$ height and $150 \mathrm{~mm}$ diameter.

Table 1. Concrete Mix Design

\begin{tabular}{cc}
\hline Component & Quantity $\left(\mathbf{k g} / \mathbf{m}^{3}\right)$ \\
\hline Cement & 385 \\
Water & 205 \\
Fine Aggregate & 645 \\
Coarse Aggregate & 1145 \\
\hline
\end{tabular}

\subsubsection{Epoxy Resin and Primer}

Epoxy Miracast 1517 from Miracon was used as adhesive to bind the concrete cylinder and CFRP sheet. There are several advantages of Miracast 1517; which are good in high-temperature properties, easy to mix, hardening is not affected by humidity and high strength adhesive and harden without shrinkage. The adhesive consists of two components a Part A (liquid epoxy) and Part B (liquid hardener). Part A and Part B need to be mixed by using a ratio of $100: 30$ by weight to ensure the reaction of epoxy is effective to act as the binding agent. The layer thickness of epoxy applied at the surface of the concrete cylinder is approximately less than $5 \mathrm{~mm}$. Meanwhile, Primer 8450 has been used as a primer coating. It is also consist of Part A and Part B which need to be mixed with the ratio of 100:35. The detailed properties of epoxy resin and primer provided by Miracon Sdn Bhd are given in Table 2.

Table 2. Properties of Epoxy Resin and Primer

\begin{tabular}{ccc}
\hline Type & Properties & Value \\
\hline & Mixing Ratio & $100: 30$ (weight) \\
Epoxy & Mix Viscosity $\left(23^{0} \mathrm{C}\right)$ & 400 \\
Miracast & Density & $1.13 \mathrm{~g} / \mathrm{cm}^{3}$ \\
1517 & Tg & $80^{\circ} \mathrm{C}$ \\
\hline & Mixing Ratio & $100: 35$ (weight) \\
Primer 8450 & Mix Viscosity $\left(25^{\circ} \mathrm{C}\right)$ & 2000 \\
& Density & $1.20 \mathrm{~g} / \mathrm{cm}^{3}$ \\
& Compression Strength & $90 \mathrm{~N} / \mathrm{mm}^{2}$ \\
& Elongation & $5 \%$ \\
\hline
\end{tabular}




\subsubsection{Carbon Fiber Reinforced Polymer (CFRP)}

The carbon fiber-reinforced polymer (CFRP) sheet used in this study is manufactured by Sika Kimia Sdn Bhd. The CFRP is high strength material that is bonded to structures for strengthening purposes. Furthermore, strengthening using CFRP sheet also offers the additional benefits of being able to conform to almost any complex or geometric shape such as cylinder shape. The use of CFRP by Sika gives several unique benefits such as ease of handling, high strength, lightweight, effectiveness for both wet and dry lay-up applications and significant gain in load-bearing capacity. The details properties of CFRP are given in Table 3. Figure 1 below shows the CFRP sheet used in this study.

Table 3. Properties of CFRP

\begin{tabular}{cc}
\hline Properties & Value \\
\hline Tensile Strength & $960 \mathrm{~N} / \mathrm{mm}^{2}$ \\
Tensile Modulus & $73,100 \mathrm{~N} / \mathrm{mm}^{2}$ \\
Elongation & $1.33 \%$ \\
Nominal Thickness & $1 \mathrm{~mm}$ \\
Tensile Strength & $24.7 \mathrm{kN}$ \\
\hline
\end{tabular}

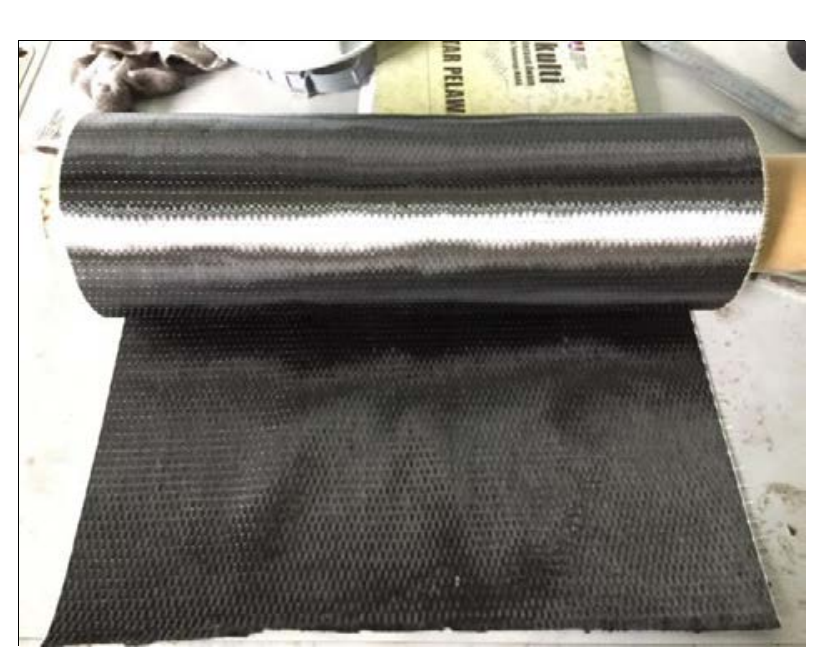

Figure 1. CFRP Sheet

\subsubsection{Fire Protection Mortar}

The fire protection mortar used in this experiment is also manufactured by Sika Kimia Sdn Bhd with the code name Sikacrete-213 FMY. Sikacrete-213 FMY is applicable for the use in concrete, reinforced concrete, CFRP and steel structure exposed to fire hazards. It contains phyllosilicate aggregate, which is highly effective in resisting the heat of hydrocarbon fires. The advantages of this fire protection mortar are easy to apply with a minimal rebound, lightweight, low density and minimal layer thickness of $15 \mathrm{~mm}$ to meet specifications. The detailed properties of Sikacrete-213 FMY are given in Table 4.
Table 4. Properties of Fire Protection Mortar

\begin{tabular}{cc}
\hline Properties & Value \\
\hline Density & $0.57 \mathrm{~kg} / \mathrm{l}$ \\
Compressive Strength & $2.0 \mathrm{~N} / \mathrm{mm}^{2}$ \\
Thermal Conductivity & $0.23 \mathrm{~W} / \mathrm{m} . \mathrm{K}$ at $+10^{\circ} \mathrm{C}$ \\
Consumption & $6 \mathrm{~kg} / \mathrm{m}^{2}$ for a layer thick $10 \mathrm{~mm}$ \\
Layer Thickness & Min $15 \mathrm{~mm}$ without \\
& reinforcement \\
Ambient Air Temperature & $25 \mathrm{~mm}$ with reinforcement \\
Substrate Temperature & $+5^{\circ} \mathrm{C}$ min $/ 35^{\circ} \mathrm{C}$ max \\
& $+5^{\circ} \mathrm{C}$ min $/ 35^{\circ} \mathrm{C}$ max \\
\hline
\end{tabular}

\subsubsection{Specimen Preparation}

Prior to the CFRp wrapping process, the surface of the concrete has to be prepared accordingly. In this phase, the surface of concrete needs to be cleaned and smoothed. The sandpaper was used to smoothen the concrete surface. The surfaced also must be sound and free from any oil laitance. Any water ponding must be wiped dry before application of epoxy primer. After that, a thin layer of epoxy primer was applied, followed by the epoxy resin. The two-component of the epoxy system which consists of Part A and Part B were mixed by hand for at least 5 minutes with a slow speed (25-30 cycles of stir in a minute) in order to avoid unnecessary air bubbles. One layer of CFRP sheet was then wrapped around the specimens.

During the wrapping process of the concrete cylinders, special care was taken in order to achieve the perfect bonding between the CFRP sheet and the concrete surface. All entrapped air in between the surface and CFRP was removed. Finally, a thick layer of epoxy resin was applied on the top surface of CFRP. All specimens were then stored in room temperature for 24 hours for the curing process of the epoxy to take place. Another three (3) samples of the CFRP concrete cylinder were protected with Sikacrete -213 FMY fire protection mortar. The fire protection mortar powder was mixed with a ratio of $10.9 \mathrm{~L}$ of portal water to $13 \mathrm{~kg}$ of fire protection mortar powder. The mix was blended to a uniform consistency for a minimum of 3 minutes. A thick layer of epoxy resin was then applied on the top surface of the CFRP sheet and before the epoxy layer dries, the fire protection mortar was applied on the surface of the CFRP sheet. CFRP concrete cylinder insulated was then stored in room temperature for 4 days for curing.

Once the epoxy and fire protection mortar cured, then specimens were exposed to high temperature of $600^{\circ} \mathrm{C}$ and $800^{\circ} \mathrm{C}$. The specimens were heated in an electric furnace having $250 \mathrm{~mm}$ x $1000 \mathrm{~mm}$ x $250 \mathrm{~mm}$ size after more than one month of casting at a rate of $5^{\circ} \mathrm{C} / \mathrm{min}$. The temperatures within the furnace were controlled by two type-K thermocouples installed at mid-height and at the top of the electric furnace. When the average furnace temperatures reached $600^{\circ} \mathrm{C}$ or $800^{\circ} \mathrm{C}$, the furnace temperatures were kept constant for one hour. The furnace 
was switched off and the cubes were allowed to cool down naturally inside the furnace. The used of $600^{\circ} \mathrm{C}$ was referred to the previous researcher [11] in the study of elevating the effect of temperature on compressive and tensile strength of concrete with admixture. Meanwhile the used of temperature of $800^{\circ} \mathrm{C}$ was to test the cylinders whether both unconfined and confined cylinders could withstand the high temperature or not. The mentioned temperatures were defined as high temperature as the temperature exceeds the ambient temperature which was $27^{\circ} \mathrm{C}$ to $28^{\circ} \mathrm{C}$. The cover of the furnace was lifted off when the temperature inside the furnace reached ambient temperature. The specimens were then taken out of the furnace and stored in a dry condition at room temperature for a day before testing. Figure 2 below shows the specimens that are ready to be burnt in an electric furnace.

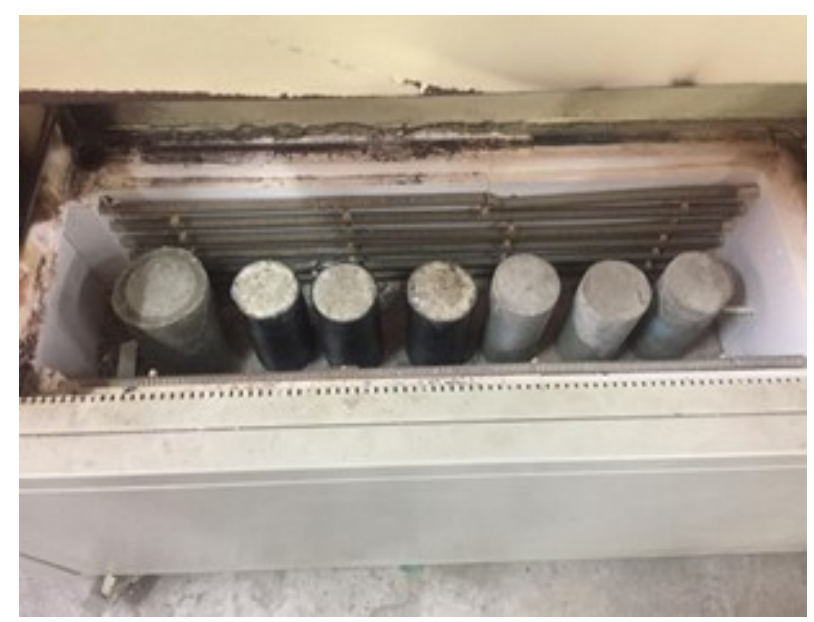

Figure 2. Specimens in the Electric Furnace

\subsubsection{Compression Test}

Eighteen (18) specimens including control samples, CFRP concrete cylinder and CFRP concrete cylinder insulated with fire protection mortar were tested using a compression machine to determine the compressive strength of concrete for 28 days. The specimen was placed on the adjusted platform of the compression machine. A few parameters were programming into the machine such as the dimension of concrete $(300 \mathrm{~mm}$ height $\mathrm{x} 150 \mathrm{~mm}$ diameter) and the pace rate $(6.8 \mathrm{kN} / \mathrm{s})$. The pace rate is the rate of the quantity of loading applied on the specimens. Loading was applied gradually without shock and it was increased continuously. The formula to determine pace rate (1) is shown below.

$$
\text { Pace Rate, } \mathrm{kN} / \mathrm{s}=(140 \times 9.81) \frac{\mathrm{A}}{1000 \times 60}
$$

The result of the compressive strength of the concrete was obtained when the concrete failed, and the result was displayed on the machine. The result showed the compressive strength in $\mathrm{N} / \mathrm{mm}^{2}$. The compressive strengths were recorded for each sample.

\section{Result and Discussion}

The results from the experiment will cover the compressive strength and the mode of failure of the concrete cylinder specimens.

\subsection{Compressive Strength}

The control sample at ambient temperature was tested at 28 days. The average compressive strength of the sample is $32.9 \mathrm{~N} / \mathrm{mm}^{2}$. When control samples were exposed to $600^{\circ} \mathrm{C}$, the average compressive strength was $23.7 \mathrm{~N} / \mathrm{mm}^{2}$. The average strength loss of the sample was about $28 \%$. A similar result was found by [12], the study of the effects of high temperature on compressive and flexural strengths of ordinary and high-performance concrete. A $34 \mathrm{MPa}$ compressive strength of ordinary concrete was exposed to $600^{\circ} \mathrm{C}$. After the sample was cooled down in the air, the compressive strength was reduced to $27 \%$. For control samples exposed to $800^{\circ} \mathrm{C}$, a compressive test on samples could not be completed because concrete samples were disintegrated during heating. Meanwhile, for the CFRP wrapped concrete cylinder, only samples exposed to $600^{\circ} \mathrm{C}$ were tested for the compressive test. Meanwhile, for insulated and non-insulated samples exposed to $800^{\circ} \mathrm{C}$, compressive test on samples could not be completed because concrete samples were disintegrated during heating and the bonding between CFRP and concrete surface suffered a total loss. The average compressive strength of the CFRP concrete cylinder exposed to $600^{\circ} \mathrm{C}$ is $25.8 \mathrm{~N} / \mathrm{mm}^{2}$. The compressive strength was increased by about $9 \%$ compared to the control sample. This could be concluded, when the CFRP concrete cylinder was exposed to $600^{\circ} \mathrm{C}$ (7.5 Tg epoxy resin) without any protection, the adhesion strength of the adhesive and concrete surface was too low. Table 5 and Table 6 below showed the compressive strength for control samples and CFRP confined samples, respectively.

Table 5. Compressive Strength of Control Samples

\begin{tabular}{cccc}
\hline Sample & $\begin{array}{c}\text { Exposure } \\
\text { Condition }\end{array}$ & $\begin{array}{c}\text { Compressive } \\
\text { Strength of } \\
\text { Concrete } \\
\text { Cylinder } \\
\left(\mathbf{N} / \mathbf{m m}^{2}\right)\end{array}$ & $\begin{array}{c}\text { Average } \\
\text { Compressive } \\
\text { Strength of } \\
\text { Concrete Cylinder } \\
\left(\mathbf{N} / \mathbf{m m}^{2}\right)\end{array}$ \\
\hline 1 & Ambient & 31.4 & 32.9 \\
2 & Temperature & 33.5 & \\
3 & High & 24 & 23.7 \\
1 & Temperature & 23.4 & \\
\hline 3 & $\left(600^{\circ} \mathrm{C}\right)$ & 23.7 & \\
\hline 1 & High & - & \\
2 & Temperature & - & \\
\hline 3 & $\left(800^{\circ} \mathrm{C}\right)$ & - & \\
\hline
\end{tabular}


Table 6. Compressive Strength of CFRP Confined Samples

\begin{tabular}{|c|c|c|c|}
\hline Sample & $\begin{array}{l}\text { Exposure/ } \\
\text { Specimen } \\
\text { Condition }\end{array}$ & $\begin{array}{l}\text { Compressive } \\
\text { Strength of } \\
\text { Concrete } \\
\text { Cylinder } \\
\left(\mathbf{N} / \mathbf{m m}^{2}\right)\end{array}$ & $\begin{array}{c}\text { Average } \\
\text { Compressive } \\
\text { Strength of } \\
\text { Concrete } \\
\text { Cylinder } \\
\left(\mathbf{N} / \mathbf{m m}^{2}\right) \\
\end{array}$ \\
\hline 1 & \multirow{3}{*}{$\begin{array}{c}\text { High } \\
\text { Temperature } \\
\left(600^{\circ} \mathrm{C}\right)\end{array}$} & 24.2 & \multirow{3}{*}{25.8} \\
\hline 2 & & 26.3 & \\
\hline 3 & & 26.8 & \\
\hline
\end{tabular}

\subsection{Mode of Failure}

\subsubsection{Unconfined Specimens}

The crack and discoloration of the specimen were observed and noted after heating them in the electrical furnace at a temperature of $600^{\circ} \mathrm{C}$ and $800^{\circ} \mathrm{C}$ and letting them cool. At the temperature of $600^{\circ} \mathrm{C}$, the overall color of the specimen changed to whitish-grey and at the temperature of $800^{\circ} \mathrm{C}$, the overall specimen changed to whitish color.

In view of the crack occurrence, no cracks were observed visually at the temperature of $600^{\circ} \mathrm{C}$. Meanwhile, the specimen experienced extensive crack and lead to separation of concrete at temperature of $800^{\circ} \mathrm{C}$. The post-heating observation could be seen in the in Figure 4 below. When exposing to high temperatures, the chemical composition and physical structure of the concrete changed considerably. The separation of concrete was the result of moisture driven out during heating, the incompatibility in thermal expansion between the cement paste and aggregates, the dehydration of the cement pastes above and the decomposition of the limestone aggregate.

\subsubsection{Confined Specimen}

A concrete cylinder wrapped with CFRP was carefully observed to identify their conditions after exposing them to $600^{\circ} \mathrm{C}$ and $800^{\circ} \mathrm{C}$. Specimens shown in Figure 3 depicted the effect of $600^{\circ} \mathrm{C}$ temperature on the CFRP concrete cylinder. The CFRP sheet was found to be charred. Meanwhile, the condition CFRP concrete cylinder at $800^{\circ} \mathrm{C}$ is shown in Figure 5. CFRP sheet combusted during heating. A little piece of CFRP was noticed on the base of the electric furnace and the condition of the concrete cylinder was extremely bad with extensive crack and separation between cement pastes.

Figure 6 represented the condition of the CFRP concrete cylinder insulated with fire protection mortar. All specimens experienced the same deteriorated pattern. Spalling of concrete only occurred on the top of concrete. It was found epoxy resin was oxidized on the electrical furnace during heating. The bond between the CFRP sheet and concrete surface was totally detached due to adhesive softening and oxidizing but CFRP sheet did not experience any combustion. Figure 6 (c) showed the condition of concrete cylinder. The presence of fire protection mortar in this study was found to be effective in avoiding the separation of concrete as compared to non-insulated. Only hair cracks with approximately 0.05 $\mathrm{mm}$ width were present on the specimens.
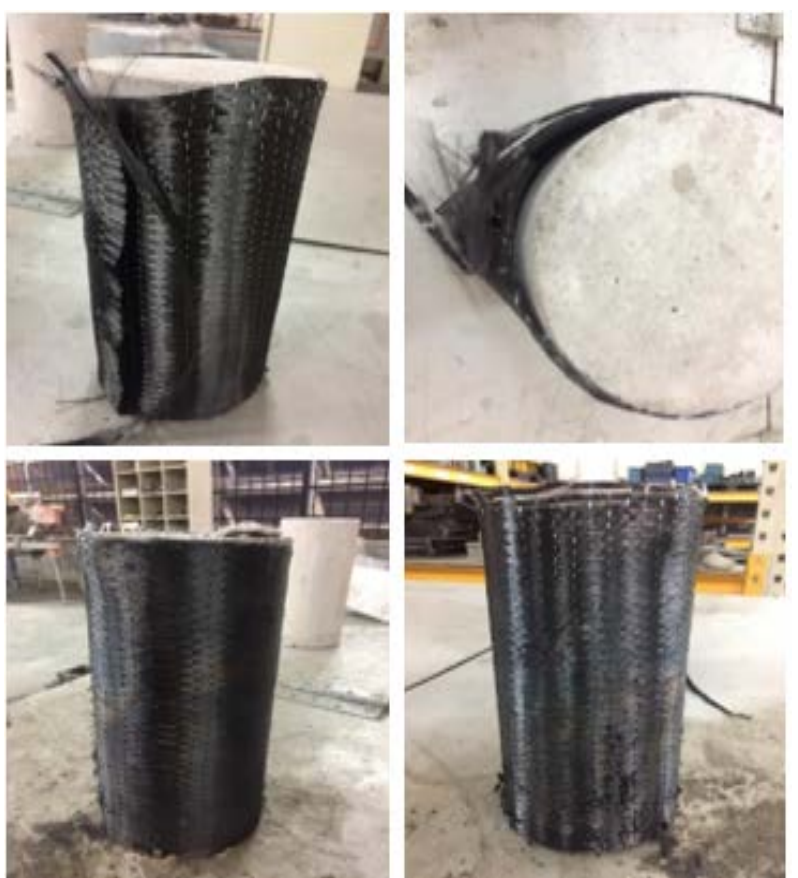

Figure 3. Condition of Confined Samples after $600^{\circ} \mathrm{C}$ Exposure

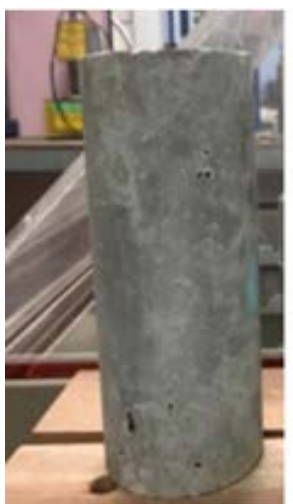

A (Ambient temperature)

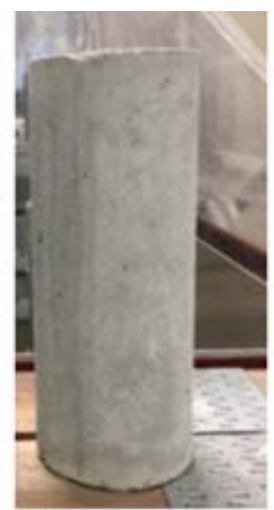

$\mathrm{B}\left(600^{\circ} \mathrm{C}\right)$

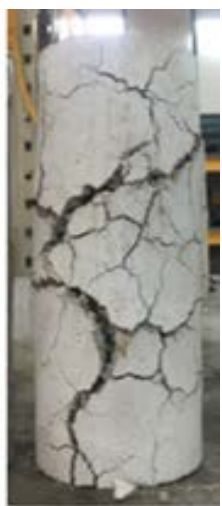

$\mathrm{C}\left(800^{\circ} \mathrm{C}\right)$
Figure 4. Post-Heating Observation
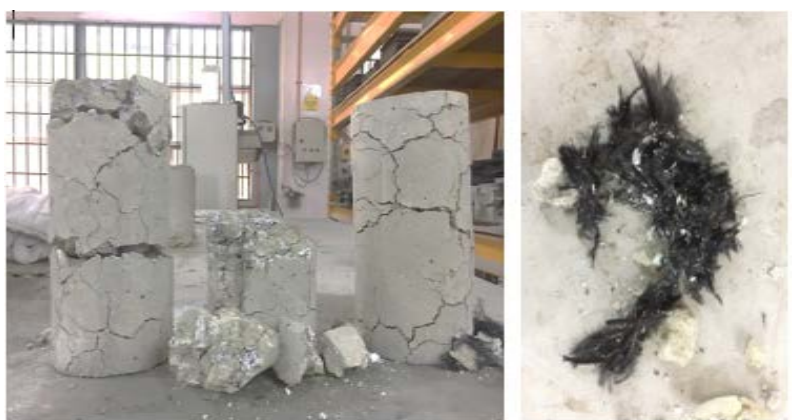

Figure 5. Condition of Confined Samples After $800^{\circ} \mathrm{C}$ Exposure 


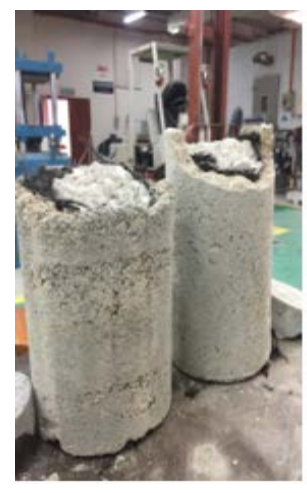

a

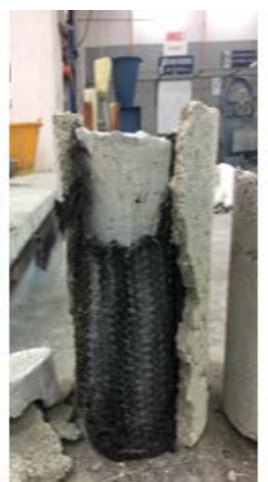

$\mathrm{b}$

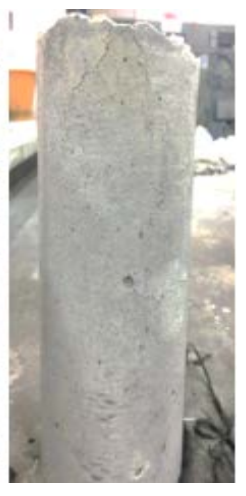

C
Figure 6. Condition of Confined Samples after $800^{\circ} \mathrm{C}$ Exposure

\section{Conclusions and Recommendation}

The average strength loss of the control sample (without CFRP), when exposed to $600^{\circ} \mathrm{C}$, is about $28 \%$ as compared to control samples exposed to ambient temperature with no cracks were observed visually during the experiment. However, the bonding between the CFRP sheet and concrete cylinder had decreased. The average compressive strength of the CFRP concrete cylinder exposed to $600^{\circ} \mathrm{C}$ is increased about $9 \%$ compared to the control sample (without CFRP and exposed to $600^{\circ} \mathrm{C}$ ). When the CFRP concrete cylinder is exposed to $600^{\circ} \mathrm{C}$ without any protection, the adhesion strength of the adhesive and concrete surface is extremely low. The CFRP sheets were tore and combusted at $800^{\circ} \mathrm{C}$ and the epoxy began to melt and detached at temperature of $200^{\circ} \mathrm{C}$.

The temperature of $800^{\circ} \mathrm{C}$ cannot be used to test the concrete cylinder without fire protection mortar because the temperature is too high and the samples will be damaged before compression test can be performed. Fire protection mortar can prevent the concrete cylinder from spalling, major cracks and combustion of CFRP even with a high temperature of $800^{\circ} \mathrm{C}$.

\section{Recommendation}

Future research can consider different concrete grades, different numbers of wrapping layers, different types of fire protection material as well as various types of adhesive to resist the effect of high temperature.

\section{Acknowledgments}

The authors would like to acknowledge The Research Management Centre (RMC) of UiTM and the Ministry of Higher Education Malaysia (MOHE) for the financial support of this research. This research is supported by
MOHE under the Fundamental Research Grant Scheme (FRGS) (Grant Reference No: FRGS/1 /2018/TK01/UiTM/03/4).

\section{REFERENCES}

[1] Q. Xie, L. Zhang, S. Yin, B. Zhang, and Y. Wu, Effects of high temperatures on the physical and mechanical properties of carbonated ordinary concrete, Advance in Materials of Science Engineering, Vol. 2019, 2019.

[2] J. Lee, J. Choi, D. Hwang, and I. Kwahk, Seismic performance of circular hollow RC bridge columns, KSCE Journal of Civil Engineering, Vol. 19, 1456-1467, 2015.

[3] D. Cree, P. Pliya, M. F. Green, and A. Noumowé, Thermal behaviour of unstressed and stressed high strength concrete containing polypropylene fibers at elevated temperature, Journal of Structural Fire Engineering, Vol. 8, No. 4, 402417, 2017.

[4] D. K. Rajak, D. D. Pagar, P. L. Menezes, and E. Linul, Fiber-reinforced polymer composites: Manufacturing, properties, and applications, Polymers (Basel), Vol. 11, No. 10, 2019.

[5] C. A. and A. M. A. Micelli F., Pre-load effect on CFRP-confinement of concrete columns: experimental and theoretical study, Crystals, Vol. 7, 1-7, 2021.

[6] H. M. Elsanadedy, Residual compressive strength of high-strength concrete exposed to elevated temperatures, Advanced Materials of Science Engineering, Vol. 2019, 2019.

[7] H. Elsanadedy and T. Almusallam, Effect of high temperature on structural response of reinforced concrete circular columns strengthened with fiber reinforced polymer composites, Journal of Composite Materials, 1-23, 2016.

[8] S. Sieberer, S. Nonn, and M. Schagerl, Fatigue behaviour of discontinuous carbon-fibre reinforced specimens and structural parts, International Journal of Fatigue, Vol. 131, No. July 2019, p. 105289, 2020.

[9] Antonius, A. Widhianto, D. Darmayadi, and G. D. Asfari, Fire resistance of normal and high-strength concrete with contains of steel fibre, Asian Journal of Civil Engineering, Vol. 15, No. 5, pp. 655-669, 2014.

[10] R. D. Shlla and K. I. Mohammad, Experimental Investigation on CFRP-Confined Low Strength Concrete after High-Temperatures Exposure, IOP Conference Series: Materials Science and Engineering, Vol. 1094, No. 1, p. 012086, 2021.

[11] S. Al Razib and F. I. Rahman, Elevating the effect of temperature on compressive and tensile strength of concrete with admixture elevating the effect of temperature on compressive and tensile strength of concrete with admixture, International Journal of Advanced Structure Geotechnic Engineering, Vol. 6, No. 1, pp. 12-20, 2017. 
[12] M. Husem, The effects of high temperature on compressive and flexural strengths of ordinary and high-performance concrete, Fire Safety Journal, Vol. 41, No. 2, pp. 155-163, 2006. 